\title{
ESTUDIO DE IMÁGENES DE ARTICULACIÓN PATELOFEMORAL: ¿EN QUÉ ESTAMOS?
}

Drs. Edith Miranda V(1), Sara Muñoz Ch(1), Paola Paolinelli G(1), Claudia Astudillo A(1), Mauricio Wainer E(2), Jaime Duboy U(2).

1. Unidad Musculoesquelética, Diagnóstico por Imágenes Clínica Las Condes. Santiago - Chile.

2. Departamento de Ortopedia y Traumatología, Clínica Las Condes. Santiago - Chile.

IMAGING STUDIES OF THE PATELLOFEMORAL JOINT: CURRENT REALITY

\begin{abstract}
Patellofemoral dysfunction (PFD) is a common cause for medical consultation and in a broad sense it refers to a condition in which the patella fails to engage securely in the trochlear groove. This is a topic in which terminology is often ambiguous and confusing due, inter alia, to the discrepancy between symptomatology, imaging findings and physical examination. In addition, PFD has a multifactorial etiology that includes local anatomical, rotational and dynamic factors, with no certainty about its real influence. From the imaging point of view, there are countless publications proposing different classifications and measurements obtained trough different imaging techniques; however, there is no consensus regarding what are the anatomical alterations or the normal values that imaging reports should include. A review of the existing literature is performed and we propose that patients with PFD should undergo both a radiological study comprising etiologic and anatomic factors and a second-line tomographic exploration including lower extremity rotational profiles. From the radiological and clinical viewpoints, relevant issues to be considered as well as assessments performed should be systematized and recorded in a report sheet.

Keywords: Anatomical factors, Dynamic factors, Patellar subluxation, Patellar tilt, Patellofemoral dysfunction, Trochlear dysplasia.
\end{abstract}

Miranda $\boldsymbol{E}$ y cols. Estudio de imágenes de articulación patelofemoral: ¿En qué estamos? Rev Chil Radiol 2010: 16(3): 101-115.

Correspondencia: Dra. Edith Miranda V.

Lo Fontecilla 410, Las Condes, Santiago.

edithmirandav@gmail.com

Trabajo recibido el 20 de julio de 2010, aceptado para publicación el 31 de agosto de 2010.
Resumen: La disfunción patelofemoral (DPF) es causa frecuente de consulta clínica y se refiere, a grandes rasgos, a una patología en la cual la patela falla en la correcta entrada en la tróclea. Es un tema en el que la terminología suele ser ambigua y confusa, debido entre otras cosas a la discrepancia entre la clínica y la imaginología. Además, la etiología de la DPF es multifactorial, incluyendo factores anatómicos locales, rotacionales y dinámicos, no existiendo tampoco claridad acerca de su real influencia.

Desde el punto de vista imaginológico, existen innumerables publicaciones, con diferentes clasificaciones y mediciones descritas para las distintas técnicas, sin embargo, no hay un consenso amplio en relación a cuáles son las alteraciones anatómicas o los valores normales que el reporte imaginológico debiera incluir. Se realiza una revisión de la literatura existente y se propone para los pacientes con DPF, un estudio radiológico que considera los factores etiológicos anatómicos y un estudio tomográfico de segunda línea, que incluye estudio rotacional de extremidades inferiores, sistematizando las mediciones y puntos relevantes en una plantilla de informe.

Palabras clave: Disfunción patelofemoral, Factores anatómicos, Factores dinámicos, Displasia troclear, Subluxación patelar, Tilt patelar.

\section{Introducción}

El dolor anterior de rodilla es una causa muy frecuente de consulta en ortopedia y traumatología. La disfunción patelofemoral (DPF) se refiere, en grandes rasgos, a una patología en la cual la patela falla en la correcta entrada en la tróclea. Es un tema complejo, en el que la terminología suele ser ambigua y confusa. Esta falta de claridad se debe, entre otras cosas, a la discrepancia entre la sintomatología, la imaginología y el examen físico.

En las alteraciones de esta articulación existe menos conocimiento que en cualquier otra condición patológica de la rodilla. La mecánica patelofemoral 
es compleja y la etiología de su patología es multifactorial.

En los estudios por imágenes existe un amplio rango de normalidad y la terminología también es confusa en la comunidad científica, entrecruzándose términos de ciencias básicas con diagnósticos clínicos y síndromes que no direccionan el diagnóstico etiológico ni el enfoque terapéutico, según lo establece el Grupo Internacional de Estudio de la patología Patelofemoral (IPSG). Se utilizan diferentes términos como: mal-alineamiento patelofemoral, condromalacia patelofemoral, inestabilidad patelofemoral, dolor anterior de rodilla y disfunción patelofemoral para referirse al mismo problema.

En esta revisión se analizan los factores anatómicos que condicionan inestabilidad patelar objetiva y se propone un protocolo de estudio por imágenes que investiga factores directos, originados en la articulación patelofemoral (APF), e indirectos, originados en alteraciones rotacionales.

\section{Desarrollo}

Hoy en día existe consenso en tratar de definir diagnósticos que reflejen la etiología del cuadro clínico, separando los factores extrínsecos como el trauma agudo y el repetitivo (sobrecarga) y los intrínsecos, que son los factores anatómicos que condicionan las alteraciones biomecánicas. Los factores anatómicos están determinados por músculos, tendones, huesos y problemas de desarrollo del aparato locomotor. Algunos de ellos pueden ser objetivados en los estudios por imágenes.

Probablemente la clasificación más útil fue propuesta en 1978 cuando Dejour, Houghston y Fulkerson $^{(1)}$ casi simultáneamente describieron el cuadro clínico de mal-alineamiento patelofemoral separándolo en 3 grandes grupos:

1. Historia de dolor patelofemoral sin factores anatómicos etiológicos.

2. Historia de dolor patelofemoral con factores anatómicos.

3. Historia de luxación con factores anatómicos.

La nomenclatura actual más utilizada tal vez sea la propuesta por el grupo francés que clasifica el problema en 3 cuadros clínicos:

1. Inestabilidad objetiva con factores anatómicos: pacientes con episodios repetidos de luxación patelofemoral.

2. Inestabilidad potencial: pacientes sin luxación pero con dolor y factores anatómicos presentes.

3. Dolor sin inestabilidad ni factores anatómi$\cos ^{(2)}$.

En la actualidad se postula que la inestabilidad patelar tendría una etiología multifactorial con factores anatómicos-morfológicos y dinámicos (Tabla I) originados en la APF y en la extremidad completa, que provocan un desequilibrio entre las fuerzas que controlan la tracción patelar durante la flexión y extensión de la rodilla, causando sobrecarga de la articulación ${ }^{(3)}$. No existe claridad acerca de la influencia real que ejercen los diferentes factores anatómicos descritos en la DPF.

Desde el punto de vista imaginológico, se cuenta con innumerables publicaciones, con diferentes clasificaciones y mediciones descritas en las distintas técnicas, sin embargo, no hay un consenso amplio en relación a cuáles son las alteraciones anatómicas o los valores normales que el reporte imaginológico debiera incluir.

\section{Evaluación imaginológica de la APF}

La evaluación de la APF debe comenzar siempre con un estudio radiológico simple (Rx simple)(4), con tres proyecciones: anteroposterior, lateral y axial con flexión menor a $30^{\circ}$. ¿Por qué menor a $30^{\circ}$ ?: porque se ha descrito que un $97 \%$ de los pacientes normales tienen la patela centrada en $30^{\circ}$ y a una mayor flexión se van a reducir la mayor parte de las anormalidades de alineamiento(5).

En la Rx simple, principalmente podemos evaluar el espacio articular femorotibial, lesiones traumáticas o tumores y hallazgos en la patela, como fracturas, patela bipartita, defecto patelar dorsal, etc. La radiografía en proyección AP es la que menos información aporta respecto a la APF (Figura 1).

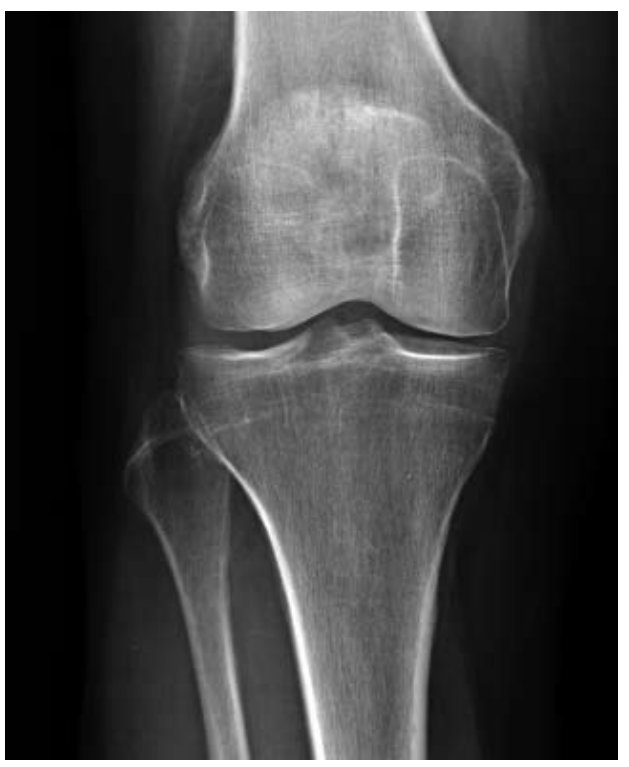

Figura 1. Proyección AP de rodilla.

La Rx en proyección lateral debe realizarse en flexión menor a $30^{\circ}$; una proyección lateral adecuada es aquella en la cual las porciones posteriores de los cóndilos femorales aparecen superpuestos. En estas condiciones se identifican tres líneas densas en la 
porción anterior de la epífisis femoral distal: las dos anteriores corresponden a los contornos anteriores de los cóndilos femorales y la posterior al surco troclear ${ }^{(6)}$ (Figura 2). Es importante conocer las limitaciones de esta proyección, dependientes tanto del tecnólogo como del paciente, ya que la variabilidad en su toma origina dificultades para obtener una proyección que se realice efectivamente en flexión menor a $30^{\circ}$.

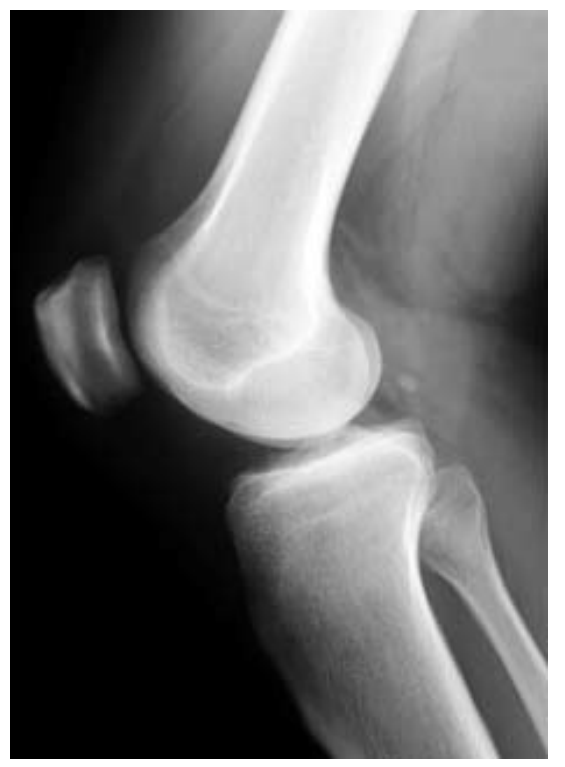

Figura 2. Radiografía lateral de buena calidad; se observan cóndilos femorales posteriores superpuestos.

La proyección axial en $30^{\circ}$ se realiza según lo descrito por Merchant $^{(7)}$, con el paciente con las rodillas flectadas, el chasis sobre las piernas y el rayo horizontal en $30^{\circ}$. Se aplican aquí las mismas consideraciones de la radiografía en proyección lateral, en cuanto a la variabilidad de la toma y dificultad de obtención de una proyección verdaderamente en menos de $30^{\circ}$ de flexión, por lo que estas mediciones en $\mathrm{Rx}$ simple tendrían un valor limitado.

La tomografía computada (TC) es una técnica que permite obtener imágenes en distintos grados de flexión, obtener mediciones más exactas que las realizadas en Rx simple y efectuar superposición de imágenes ${ }^{(5)}$. Existe además la posibilidad de realizar mediciones con contracción del cuádriceps, que según lo descrito en la literatura aumentarían la sensibilidad del estudio por empeoramiento de valores anormales y aparición de anormalidad en pacientes con valores normales en reposo(6).

La resonancia magnética (RM) permite evaluar principalmente los tejidos blandos: retináculos, tendón patelar y cuadricipital, músculo cuádriceps y cartílagos patelar y troclear, evidenciando cambios degenerativos del cartílago, lesiones condrales, etc ${ }^{(8)}$ (Figuras 3 y 4 ).

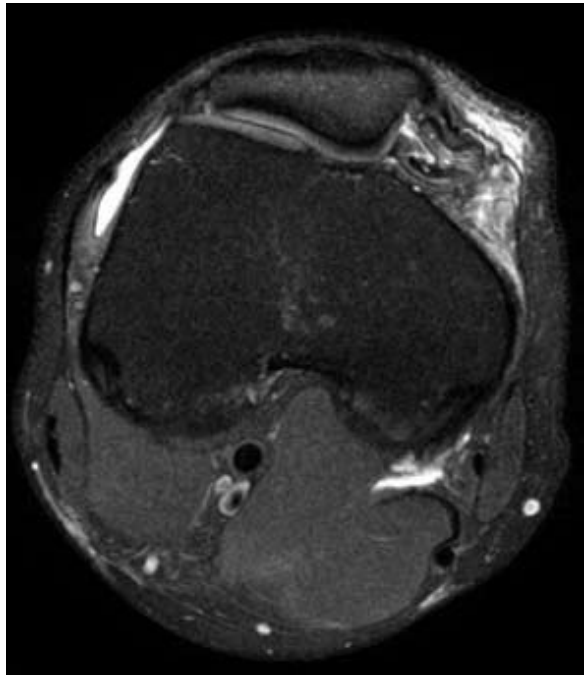

Figura 3. Luxación traumática patelar. RM secuencia DP FS axial, donde se observa rotura de retináculo medial.

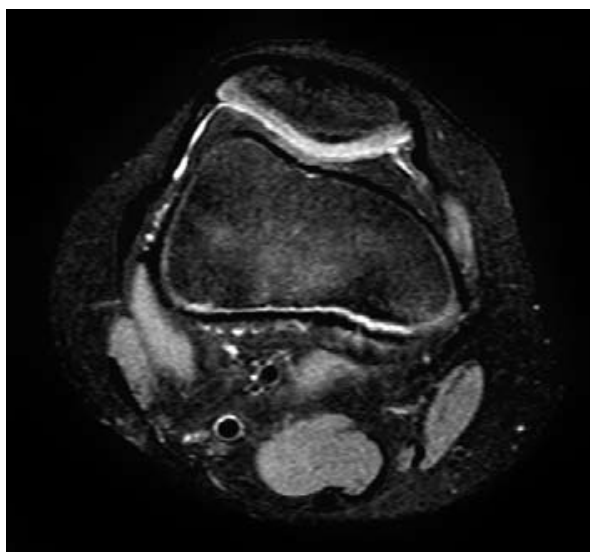

Figura 4. RM secuencia DP FS axial que muestra patela con cartílago adelgazado, de margen irregular, con alteración de señal interna, de aspecto condromalásico.

\section{Evaluación de factores dinámicos}

Se ha intentado evaluar la APF en forma dinámica, para establecer el comportamiento e interacción de las estructuras anatómicas involucradas durante la flexo-extensión.

En lo que se refiere a RM dinámica de la DPF, existen estudios para reproducir el comportamiento dinámico de la articulación en bipedestación, ya que las medidas "estáticas" de la Rx simple no revelan la relación entre la tróclea y la patela en los primeros $30^{\circ}$ de flexión. Se ha demostrado que es un medio útil y sensible, ya que permite demostrar las partes blandas que influyen en la estabilidad y la función de la articulación, información muy importante ya que anomalías en estas estructuras (tendón patelar, retináculos y cuádriceps) suelen ser factores importantes de dichas alteraciones ${ }^{(9)}$. 
con RM:

Existen varias técnicas de estudios dinámicos

1. Técnica de colocación con incremento pasivo: consiste en la obtención de múltiples imágenes axiales en distintos niveles mientras la articulación es flexionada progresivamente y de forma pasiva mediante un soporte no ferromagnético activado por el paciente. El estudio se realiza en decúbito prono y se obtienen imágenes en incrementos de $5^{\circ}$, desde 0 a $30^{\circ}$ de flexión. Algunos trabajos han demostrado que esta técnica es aceptable para evaluar la alineación y el recorrido de la patela.

2. Técnica de movimiento activo: permite obtener imágenes durante el movimiento. La principal ventaja es que considera la influencia de los músculos y tejidos blandos. Se realiza en decúbito prono desde los $45^{\circ}$ de flexión hasta la extensión. En comparación con la técnica anterior, permite un examen más fisiológico y algunas veces se hace más evidente un recorrido anormal de la patela.

3. Técnica de ciclo de cine: utiliza un soporte especial no ferromagnético, que incorpora un disparador que percibe el movimiento de la patela. Se coloca al paciente en decúbito supino, se flexiona y extiende la rodilla repetidamente. Esta técnica muestra modelos de recorrido patelar diferentes a los obtenidos mediante la técnica de colocación con incremento pasivo.

4. Técnica de movimiento activo contra resistencia: en este caso, el examen se realiza durante el movimiento activo oponiendo una carga externa. El agregar resistencia al examen permite observar alteraciones que posiblemente no se detectan en los exámenes sin carga, lo que la convierte en una mejor técnica para identificar posiciones anómalas de la patela. Se realiza en decúbito prono, con un instrumento que permite aplicar una resistencia ajustable y se analiza de forma bilateral desde $45^{\circ}$ hasta la extensión.

Todos los artículos publicados hasta el momento actual muestran que con RM dinámica se confirma la sospecha clínica de alteración del recorrido de la patela, sin embargo, se cuestiona su utilidad real. Los centros pioneros indican que el conocimiento de la alineación patelar podría influir en el tratamiento y quizás incidir en el procedimiento quirúrgico necesario, no obstante, hasta la fecha no hay estudios publicados que documenten la capacidad de la RM dinámica para orientar el tratamiento y predecir el resultado del mismo.

\section{Evaluación de factores anátomo-morfológicos}

El objetivo de esta revisión es analizar los factores etiológicos "estáticos" más relevantes que influyen en la inestabilidad patelar objetiva, que pueden ser demostrados en estudios de imágenes y, además proponer un protocolo estandarizado del informe ima- ginológico para TC incluyendo los factores locales de la APF y los indirectos, como por ejemplo alteraciones rotacionales de la extremidad inferior.

Los factores anatómicos se resumen en la Tabla I. Se clasifican en locales (originados en la propia APF) y rotacionales (originados en los ejes rotacionales de la extremidad) $)^{(1)}$ :

I. Locales: tróclea femoral, patela, tuberosidad anterior de la tibia, tejidos blandos y relación entre la tróclea y la patela.

II. Rotacionales: anteversión acetabular (AVA), anteversión femoral (AVF), torsión tibial externa (TTE), genu valgo y genu recurvatum.

Tabla I. Factores etiológicos relacionados con disfunción patelofemoral

A.- Factores anatómicos

I. Locales:

1) Tróclea femoral

2) Patela

3) Tuberosidad anterior de la tibia

4) Tejidos blandos

5) Relación entre la tróclea y la patela

II. Rotacionales:

Anteversión acetabular (AVA)

Anteversión femoral (AVF)

Torsión tibial externa (TTE)

Genu valgo, genu recurvatum

B.- Factores dinámicos

Interacción de las estructuras anatómicas

durante la flexoextensión

\section{A I. Factores anatómicos locales}

1.- Tróclea femoral: La morfología de la tróclea es un factor que condiciona la estabilidad de la patela en la articulación. La displasia troclear es una malformación anatómica localizada en el tercio superior de la superficie articular de la tróclea, que se debe a anomalías en el crecimiento de las carillas articulares, constituyendo un factor fundamental y constante en la inestabilidad patelar objetiva. La pendiente lateral poco pronunciada del cóndilo lateral es la responsable de una tróclea plana; el surco troclear es poco profundo y por lo tanto no es capaz de retener a la patela. En los casos muy severos de displasia, la carilla lateral puede ser convexa lo que se asocia a hipoplasia del cóndilo medial. En general, interesa determinar la apertura y la profundidad del surco, ya que su alteración determina displasia y, por lo tanto, inestabilidad.

¿Cómo evaluamos imaginológicamente la tróclea femoral?

- Ángulo troclear: Mide el ángulo de apertura de la tróclea, que es en promedio $138^{\circ(11)}$; se define 
displasia de la tróclea a la apertura exagerada de este ángulo. Se determina, en el corte axial, un ángulo entre el punto más profundo de la tróclea y los puntos más superiores y aneriores de ambos cóndilos femorales. Se recomienda esta medición en el corte en que la vertiente medial sea un tercio de la lateral en el corte axial de la $\mathrm{TC}^{(12)}$. Se determina la existencia de displasia troclear si el ángulo es mayor a $140^{\circ}$ (Figura 5 ).

- Profundidad troclear: Se estudia en la Rx lateral de rodilla, trazando una línea tangente a la cortical posterior del fémur distal (a), luego una perpendicular a ésta, a la altura del margen posterior y superior de los cóndilos femorales (b), finalmente una tercera línea (c) con un ángulo de $15^{\circ}$ distal a la línea b; esta línea cruza el surco troclear y las crestas condíleas. La profundidad de la tróclea corresponde, siguiendo la línea c, a la distancia en $\mathrm{mm}$ entre el fondo de la tróclea y el borde condíleo anterior. En las rodillas normales, la profundidad es de $7,8 \mathrm{~mm}$ y en las rodillas con inestabilidad patelar es de $0,1 \mathrm{~mm}^{(6)}$ (Figura 6).

- Saliente o bump - espolón supratroclear: Se mide en la Rx lateral estricta, es decir con superposición de los cóndilos femorales. Este parámetro permite localizar y cuantificar la posición del fondo de la tróclea $(A)$ en relación a la cortical anterior del fémur (B). Se traza una línea tangencial a los últimos $10 \mathrm{~cm}$ de la cortical anterior del fémur (línea x). La línea del fondo de la tróclea puede terminar por delante (valor positivo), sobre la línea cortical (valor neutro) o por detrás de ella (valor negativo) (Figura 7). El saliente es la distancia $A B$ (entre el fondo de la tróclea y la cortical anterior del fémur) y se expresa en $\mathrm{mm}$. La imagen de la saliente también se ha llamado "espolón supratroclear"; a mayor saliente, mayor displasia. Según Dejour, en rodillas normales la saliente mide en promedio $0,8 \mathrm{~mm}$ y en rodillas inestables $3,1 \mathrm{~mm}$ en promedio(6).

- Signo del entrecruzamiento: Se evalúa en la $\mathrm{Rx}$ lateral; en condiciones normales, la Rx muestra la existencia de tres líneas formadas por el contorno de los cóndilos femorales y el fondo de la tróclea. El cóndilo interno se reconoce porque presenta una muesca más anterior y menos marcada que la del cóndilo externo. La tercera línea (posterior a las dos anteriores) corresponde a la línea del fondo de la tróclea y se prolonga hacia atrás con la línea de Blumensaat en la escotadura intercondílea. En condiciones normales, la línea del fondo de la tróclea es paralela a los perfiles de los cóndilos femorales; la forma en que finaliza esta línea nos permite definir dos tipos de trócleas normales: Tipo A cuando no existe cruce entre el fondo de la tróclea y los cóndilos femorales y Tipo
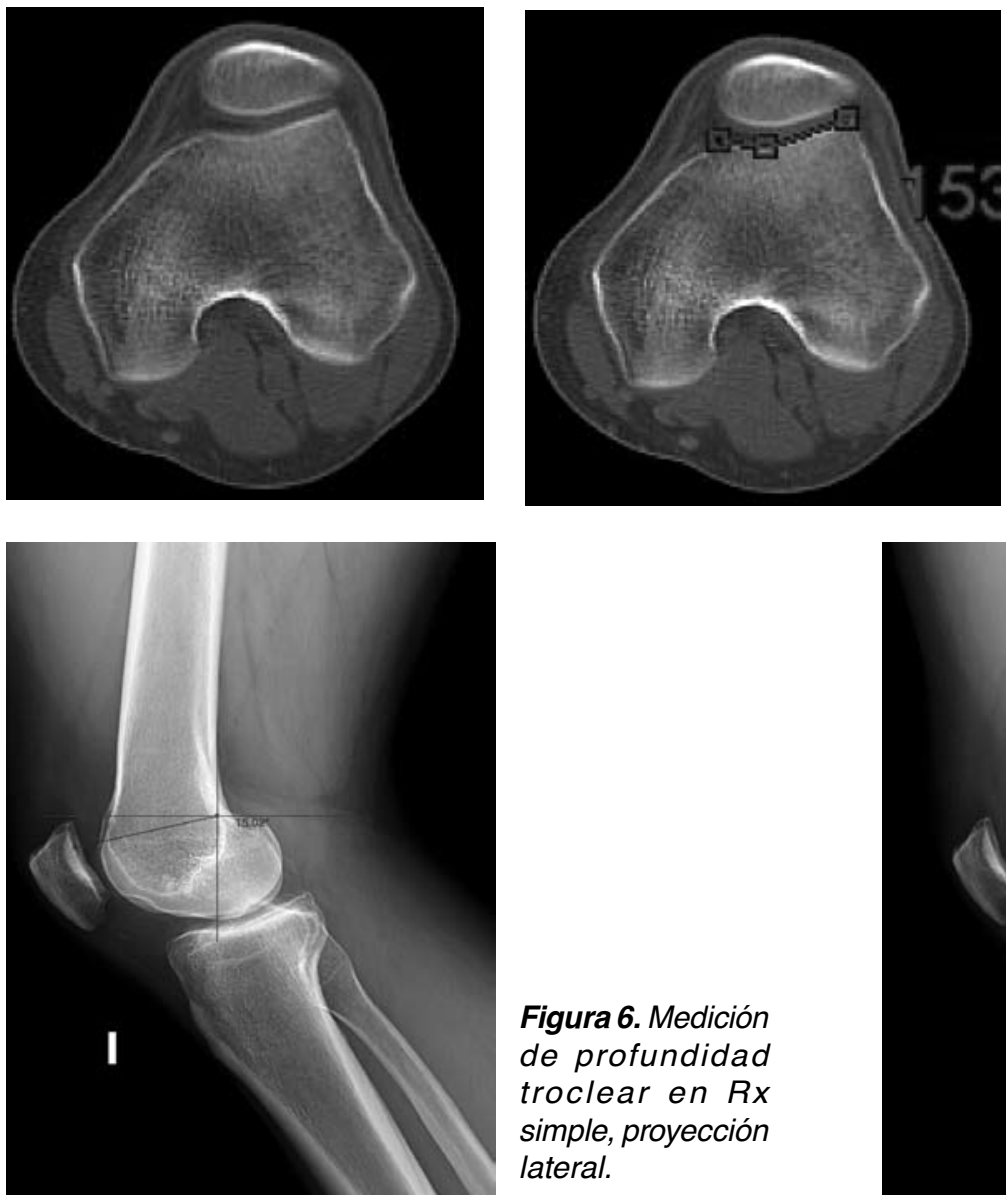

Figura 6. Medición de profundidad troclear en $R x$ simple, proyección lateral.

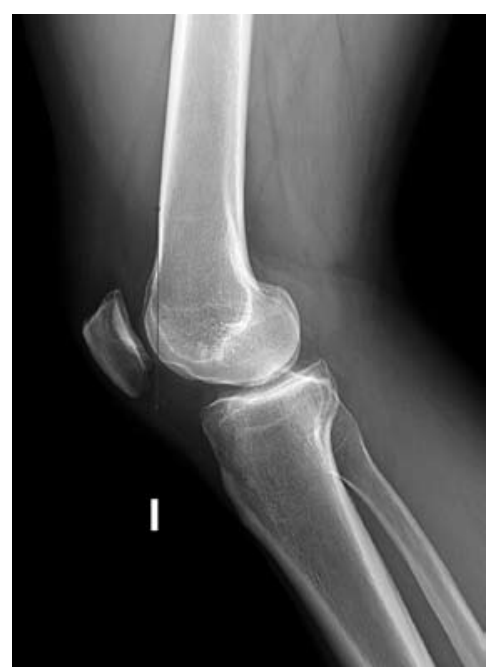

Figura 7. Bump troclear con valor negativo: línea vertical pasa por detrás del surco.
Figura 5. Ángulo troclear: Medición en TC. Se determina un ángulo entre el punto más profundo de la tróclea y los puntos más superiores y anteriores de ambos cóndilos femorales; esta medición se realizó en el punto donde la vertiente medial es un tercio de la lateral. Se determina existencia de displasia troclear si el ángulo es mayor a $140^{\circ}$. 
B cuando la línea del fondo de la tróclea cruza de modo aislado al cóndilo interno.

En la inestabilidad patelar, la línea del fondo cruza los cóndilos interno y externo más o menos abajo en función de la severidad de la displasia. Este signo es de gran valor semiológico y constituye un criterio cualitativo de displasia troclear. El signo del entrecruzamiento está presente en el $96 \%$ de las inestabilidades objetivas, en el $12 \%$ de los síndromes dolorosos rotulianos y solamente en el $2 \%$ de rodillas normales.

Dejour ha definido tres tipos de displasia en función del nivel del cruce:

Tipo I: Corresponde a la forma más leve de displasia. Las líneas de los cóndilos son simétricas y se cruzan en un mismo punto a nivel proximal en la tróclea; la tróclea es plana únicamente en la parte más superior (Figura 8a).

Tipo II: Este tipo de displasia se caracteriza por un cruce a distinto nivel de las líneas de los cóndilos. Estas líneas no se superponen, sino que la línea del fondo de la tróclea cruza primero el cóndilo interno y después el cóndilo externo; a medida que desciende el nivel del cruce aumenta la severidad de la displasia (Figura 8b).

Tipo III: Es la forma más severa. Las líneas de los cóndilos se superponen, cruzándose con la

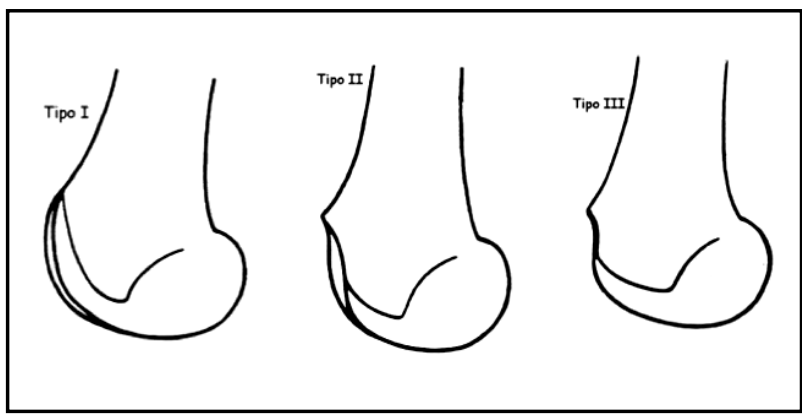

Figura 8 a,b,c. Esquema de displasia troclear tipo I, II y III según Dejour.

línea del fondo de la tróclea a un nivel muy bajo (Figura $8 \mathrm{c})^{(6)}$.

En resumen, existen varias maneras de objetivar la presencia de displasia troclear; nosotros utilizamos: el ángulo troclear, el signo del entrecruzamiento de la Rx lateral con su contraparte en TC (que será señalada con posterioridad) y la presencia de espolón supratroclear.

2.- Patela: La patela es parte del aparato extensor de la rodilla. El cartílago patelar es el más grueso del organismo y está preparado para resistir importantes fuerzas compresivas. La función de la patela es mejorar la eficacia del músculo cuádriceps al aumentar el brazo de palanca del mecanismo extensor. Esto se debe a que la patela desplaza al tendón patelar fuera del contacto femorotibial durante el movimiento, aumentando así el brazo de palanca; centraliza las fuerzas de tracción del cuádriceps hasta el tendón patelar y la tuberosidad tibial, distribuye las presiones sobre la tróclea femoral y estabiliza la rodilla durante la rotación.

- Posición: La patela alta es uno de los factores etiológicos más importantes de la inestabilidad, ya que está presente entre un $30-50 \%$ de las inestabilidades patelares objetivas ${ }^{(13)}$; ocasionalmente, es el único factor anatómico presente. Es a menudo bilateral y frecuentemente se encuentra en las luxaciones recidivantes $^{(11)}$. Está condicionada por la presencia de un tendón patelar anormalmente largo, que produce un conflicto en la entrada de la patela en la tróclea y subluxación lateral por la tensión precoz del retináculo lateral al inicio de la flexión. La patela alta da una menor estabilidad ósea porque se requiere mayor grado de flexión para que ésta se encaje en la tróclea que en una rodilla normal ${ }^{(14)}$, en la cual la patela se encaja a aproximadamente $20^{\circ}$ de flexión ${ }^{(12)}$. En la actualidad, se utiliza la $\mathrm{Rx}$ simple para realizar las medidas de la altura de la patela; se han descrito distintas mediciones, entre las que las más usadas en inestabilidad patelar objetiva son: el índice de Insall Salvatti y el índice de Caton ${ }^{(14)}$.

Según Insall Salvatti se determina la relación entre la longitud del tendón patelar y el diámetro máximo de la patela, considerándose patela alta

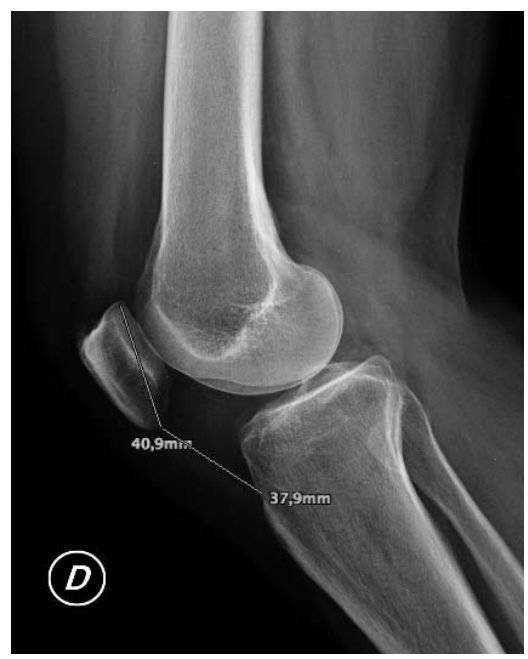

Figura 9. Insall Salvatti: medición en $R x$ simple proyección lateral. Patela alta: índice IS > a 1.2 y baja: índice $I S<a$ 0.8 .

aquella con un índice mayor a 1.2 y baja menor a $0.8^{(10)}$ (Figura 9).

Según Caton, se determina el radio entre el punto inferior desde la patela hasta el platillo tibial anterosuperior y la longitud de la cara articular de 


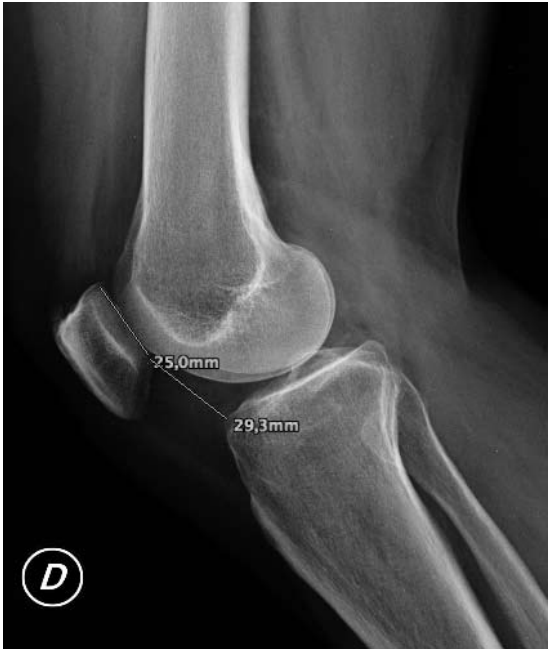

Figura 10. Caton: medición en $R x$ simple proyección lateral. Patela alta: índice > a 1.2 y baja: índice < a 0.6.

la patela; se estima como patela alta aquella con un índice mayor a 1.2 y baja menor a $0.6^{(11)}$ (Figura 10).

- Morfología: Wiberg (en 1941) clasificó a la patela según la morfología de la faceta interna en 3 tipos y Baumgartl (en 1944) añade otra variante más ${ }^{(15)}$ :

Tipo I: La faceta interna es de concavidad suave y de la misma medida que la externa. $(10 \%$ casos)

Tipo II: La faceta interna es menor que la lateral y es plana o ligeramente convexa. $(65 \%$ casos)

Tipo III: La faceta interna es muy pequeña en comparación con la lateral y es convexa (casi vertical); este tipo de patela se relaciona con inestabilidad (Figura 11).

Tipo IV: Se caracteriza por la ausencia de cresta medial o de faceta interna (gorra de caza-

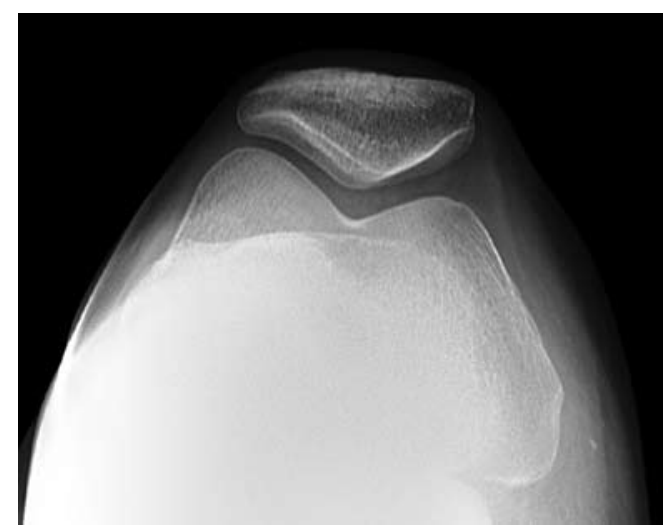

Figura 11. Wiberg tipo II: facetas patelares asimétricas, con la faceta medial de menor tamaño. dor).

3.- Tuberosidad anterior de la tibia (TAT): La posición demasiado lateral de la TAT es una de las alteraciones anatómicas mencionadas con mayor frecuencia y tal vez la que ha dado lugar a mayor número de intervenciones quirúrgicas. La posición de la TAT determina el valgo del aparato extensor de la rodilla y la distancia entre la TAT y el surco troclear da una idea del vector en valgo del aparato extensor. ¿Cómo lo evaluamos con imágenes?

Con la distancia SIT-TAT (surco intertroclear/ tuberosidad anterior de la tibia). Esta medición se realiza con superposición de cortes axiales de TC realizados a distintos niveles: uno en la tróclea, donde la vertiente medial es $1 / 3$ de la lateral, y el otro a través de la tuberosidad anterior de la tibia. Se traza una línea vertical que pasa por el punto más profundo de la tróclea y una segunda línea paralela a la anterior, que pasa por la TAT. La medición de la distancia entre ambas debe ser menor a $15 \mathrm{~mm}$ y si el valor es mayor, la distancia SIT -TAT se considera aumentada y patológica; (11) es una medida de la

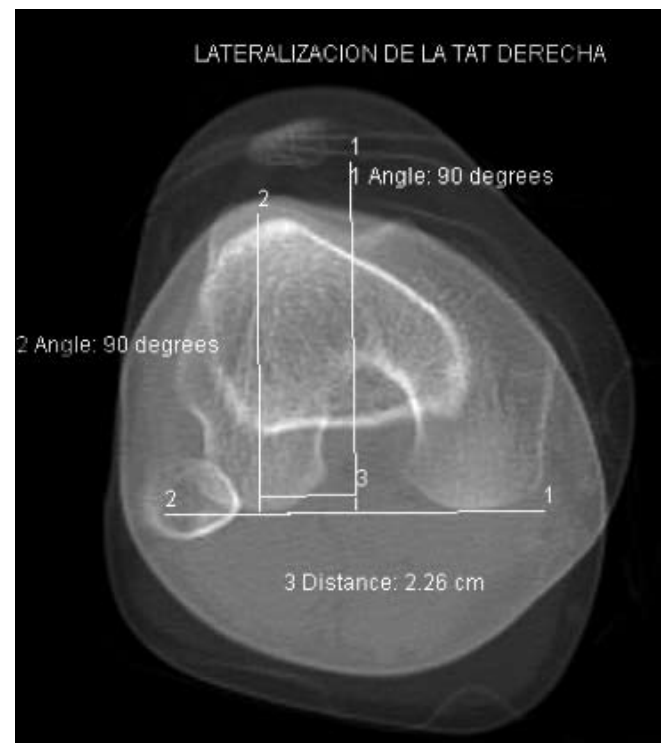

Figura 12. Medición de distancia SIT-TAT mediante superposición de cortes axiales de TC; en el ejemplo se observa aumento de la distancia SIT-TAT.

traslación externa de la TAT en relación al surco troclear en el plano sagital (Figura 12).

El ángulo $Q$ se mide entre el eje del vasto lateral del cuádriceps y el eje del tendón patelar, por ende su inserción en la TAT (Figura 13). El ángulo $\mathrm{Q}^{\left({ }^{(10)}\right.}$ traduce la fuerza de tracción del músculo cuádriceps sobre la patela, determinando la magnitud de la fuerza luxante hacia lateral; mide en forma indirecta la lateralización de la TAT o inserción distal del tendón patelar. Cuando la rodilla está cercana a la extensión, la contracción 
muscular tiende a desplazar a la patela hacia lateral por acción del ángulo Q. Durante la extensión máxima, la tibia rota externamente, desplazando la TTA hacia lateral, lo que aumenta el ángulo $Q$, maximizando la fuerza luxante hacia lateral, por lo que es en esta posición, en extensión, cuando la patela tiene más riesgo de luxación ${ }^{(3)}$.

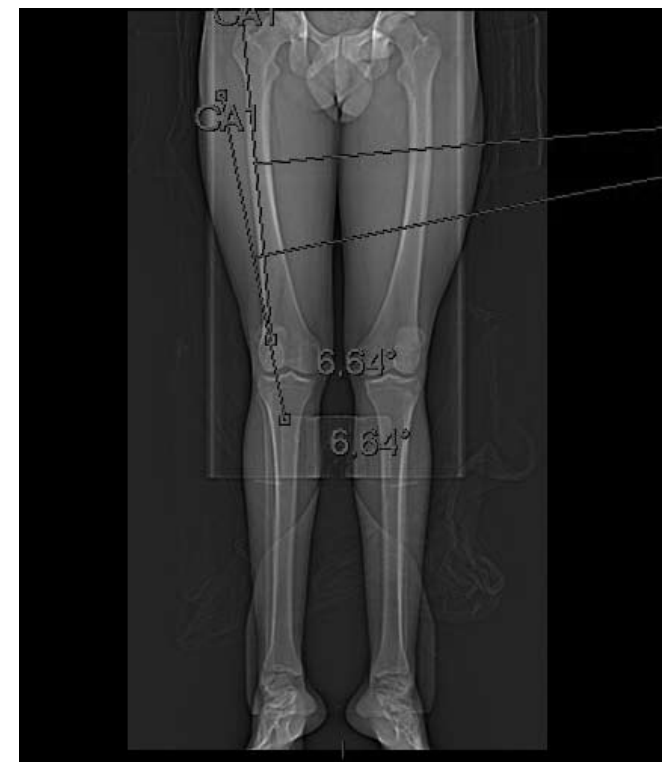

Figura 13. Ángulo Q: Se obtiene entre línea trazada desde la espina ilíaca anterosuperior al centro de la patela y otra entre el centro patelar y la tuberosidad anterior de la tibia.

\section{4.- Tejidos blandos}

- Ligamento patelofemoral medial: Es parte del retináculo medial, el principal restrictor pasivo al desplazamiento patelar lateral ${ }^{(10,12)}$. Tracciona la patela hacia medial y se ha descrito que restringe aproximadamente el $50-60 \%$ del desplazamiento lateral de la patela entre los 0 y $30^{\circ}$ de flexión ${ }^{(16)}$. No existe método de imagen para valorar su rol dinámico en la inestabilidad; en RM es posible evaluar sus características morfológicas.

- Músculo y tendón cuadricipital: Los cuatro componentes del músculo se unen distalmente en un tendón que tiene tres capas; las fibras más superficiales del recto anterior se unen a las del tendón patelar y las más profundas se insertan en el polo superior de la patela. El vasto medial y el lateral forman la capa media; estos músculos envían fibras a los retináculos. El vasto medial está formado por dos porciones, el vasto medial oblicuo y el medial largo; las fibras del vasto medial oblicuo tienen una dirección más oblicua hacia abajo y afuera y por lo tanto son más apropiadas para limitar el desplazamiento lateral de la rótula. El ángulo con que las fibras oblicuas alcanzan la patela varía entre $55^{\circ}$ y $70^{\circ}$, en relación con el eje mayor del tendón del cuádriceps. El vasto medial oblicuo se hace tendinoso a pocos milímetros de su inserción en el tercio superior o en la mitad del borde medial de la patela ${ }^{(10)}$.
Otro factor anatómico en la inestabilidad patelar es una malformación anatómica del músculo cuádriceps femoral, denominada displasia del cuádriceps. Esta anomalía morfológica presenta dos aspectos esenciales: cuádriceps corto y displasia del vasto medial. Se trata de una alteración en la inserción del vasto medial en la patela; las fibras más distales del músculo se insertan en el ángulo súpero-medial en lugar de hacerlo en el borde medial. Esta distrofia en la inserción muscular desequilibra la biomecánica del cuádriceps, aumenta el valgo del sistema extensor de la rodilla y es responsable de un aumento de las fuerzas de subluxación lateral de la patela, lo cual favorece la inestabilidad.

Algunos autores señalan la existencia de displasia en el vasto lateral, que se presenta en forma de una inserción baja anómala de las fibras del vasto lateral sobre el borde lateral de la patela, asociada a la retracción del retináculo lateral o alerón externo.

La evaluación clínica de la displasia de los vastos es subjetiva debido a la dificultad del examen. Para cuantificar la displasia, se ha propuesto que el factor indirecto medible sería la "báscula rotuliana" (rodilla en extensión), que puede estudiarse mediante TC, con y sin contracción de cuádriceps.

\section{5- Relación entre la tróclea y la patela}

La relación de estos factores anatómicos, tróclea y patela se estudia con las siguientes mediciones:

- Ángulo patelofemoral según Laurin(17): La báscula patelar se refiere a la inclinación transversal de la patela. Laurin describe la medición del ángulo patelofemoral en Rx simple, proyección axial en $20^{\circ}$ de flexión de la rodilla. Se mide trazando dos rectas, la primera corta al punto más anterior de los cóndilos y la otra es tangente a la faceta patelar lateral. El ángulo formado es positivo cuando está abierto hacia fuera, nulo cuando las dos rectas son paralelas o negativo cuando está abierto hacia dentro. Permite medir el ángulo de apertura lateral fémoropatelar, que en las rodillas normales está abierto externamente en el $97 \%$ de los casos (Figura 14).

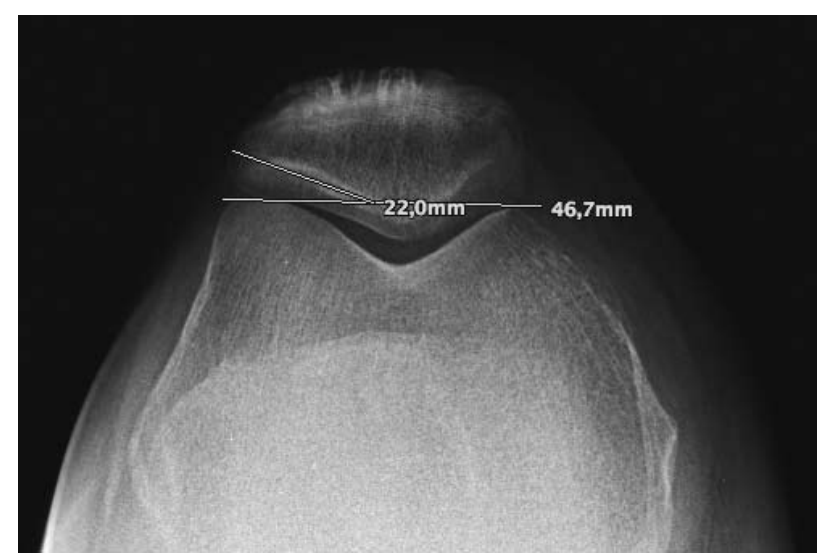

Figura 14. Ángulo patelofemoral de Laurin normal, abierto hacia lateral en $R x$ simple proyección axial en $20^{\circ}$. 
- Tilt patelar externo: Otra medición de la báscula rotuliana se realiza en TC, en el corte axial que pasa por el medio de la patela y corresponde al ángulo formado por el eje transversal de la rótula y la línea bicondílea posterior. Se realiza con la rodilla en extensión, con y sin contracción del cuádriceps, también a $15^{\circ}$ de flexión. Refleja la displasia del cuádriceps (vasto interno) y también la displasia de la tróclea. La exploración con y sin contracción del cuádriceps nos permite una evaluación dinámica de la báscula. En el $97 \%$ de los sujetos normales, la báscula es de $10^{\circ}$ a $20^{\circ}$, mientras que es superior a $20^{\circ}$ en el $83 \%$ de los pacientes con inestabilidad objetiva ${ }^{(18)}$.

- Ángulo de congruencia: El ángulo de congruencia de Merchant ${ }^{(11)}$ se utiliza para determinar subluxación patelar. Para obtenerlo se traza la bisectriz del ángulo de la tróclea en flexión y después una recta que une el fondo de la tróclea y la cresta de la patela; el ángulo formado entre éstas es el ángulo de congruencia. Si la punta de la patela está situada en el exterior de la bisectriz, el ángulo es positivo y traduce más bien una subluxación externa; si la punta está situada en el interior de la bisectriz, es negativo y traduce más bien una subluxación interna. Si el desplazamiento medial es mayor a $11^{\circ}$ y el lateral mayor a $6^{\circ}$, se determina que existe subluxación ${ }^{(11)}$ (Figura 15).

\section{A II - Factores anatómicos rotacionales}

La anatomía rotacional del fémur y de la tibia son diferentes. En el plano coronal, el fémur se dirige desde una posición de abducción a nivel proximal (debida a la anchura del anillo pélvico), hasta una posición que en teoría es ideal y que permite en los pacientes tener las tibias paralelas; en este mismo plano, la superficie articular distal del fémur tiene un valgo fisiológico de 5 a $7^{\circ}$. La tibia en el plano frontal es recta y mantiene normalmente el eje femoral; la TAT se encuentra en una posición lateral, lo que condiciona el ángulo $Q$ del aparato extensor, gracias al cual se produce un buen control de la rotación interna y del bloqueo de la rodilla en extensión máxima.

En el plano sagital, el fémur presenta una curva de concavidad posterior, mientras que la tibia presenta una importante curva de concavidad posterior en el segmento proximal a la inserción del tendón patelar, que hace que el plano de los platillos tibiales esté inclinado alrededor de $5^{\circ}$ hacia atrás.
En el plano horizontal, el fémur tiene una anteversión de aproximadamente $15^{\circ}$, que es característica de la bipedestación en el ser humano; no existe ningún otro animal con torsión femoral. Para compensar esta anteversión, existe una torsión tibial externa que se produce en los primeros centímetros de la epífisis proximal de unos $35^{\circ}$, con el objetivo que los pies estén paralelos durante la marcha ${ }^{(19)}$ Entre el fémur y la tibia se producen rotaciones que influyen en la dinámica femoro-patelar. Debido a la disposición de los ligamentos cruzados, existe una mayor capacidad de rotación externa al nivel de la rodilla, lo que lateraliza aún más la inserción del tendón patelar.

Estos factores anatómicos son entonces condicionantes indirectos de la estabilidad de la APF, por lo que resulta útil conocer además las siguientes medidas: anteversión acetabular (AVA), anteversión femoral (AVF) y torsión tibial externa $(\mathrm{TTE})^{(20)}$. Está demostrada una relación estadística entre luxación recidivante de la patela y aumento de la TTE y AVF; de igual forma, hay una asociación entre dolor anterior de rodilla si la AVF se asocia a aumento de la TTE ${ }^{(19)}$.

La versión acetabular es la normal inclinación del acetábulo en referencia al plano sagital; se define por la intersección del plano sagital del cuerpo y el plano paralelo a los bordes del acetábulo. Estudios histomorfométricos han demostrado que la anteversión acetabular permanece constante durante la primera mitad de la vida intrauterina ${ }^{(21)}$. La versión acetabular, permanece relativamente constante durante la niñez con un valor promedio de $13^{\circ(22)}$. Estos hallazgos sugieren que la versión acetabular no es un factor común en los problemas rotacionales. Para evaluar estas medidas se utiliza la capacidad de la TC que permite realizar superposición de cortes realizados a distintos niveles.

La AVF es el ángulo formado por el eje del cuello femoral y la línea bicondílea posterior ${ }^{(23)}$ y la TTE es el ángulo formado por la tangente posterior de la epífisis tibial y el eje bimaleolar ${ }^{(23)}$; los valores normales de ambas mediciones se describen posteriormente.

\section{Propuesta}

La inestabilidad patelar o DPF es una patología multifactorial y el rol actual de la imaginología sería entonces objetivar los factores anatómicos "estáticos" determinantes de la inestabilidad patelar. El estudio
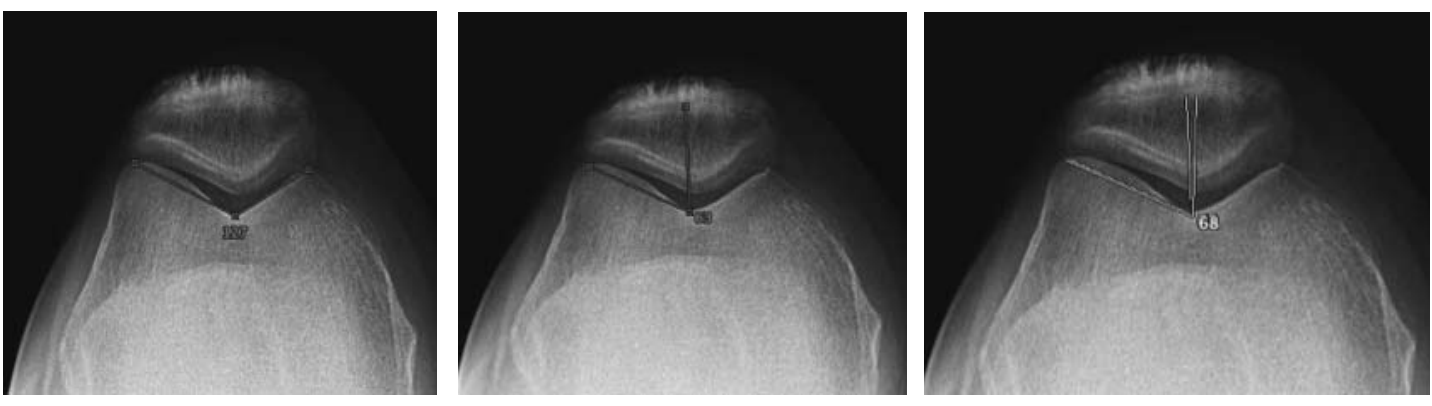

Figura 15. Ángulo de congruencia según Merchant en $R x$ simple proyección axial en $20^{\circ}$. 
imaginológico de la APF ha ido evolucionando con el tiempo, en conjunto con la aparición de distintas técnicas de estudio, utilizando en la actualidad la $R x$, la TC e incluso la RM para su evaluación.

Se propone que el estudio de la inestabilidad patelar debe incluir Rx simples, según lo descrito, y como examen de segunda línea, TC que incluye un estudio rotacional de extremidades inferiores, en el que se refleja un intento de determinar los puntos más importantes de referencia frente al estudio de la inestabilidad patelar.

\section{Estudio por tomografía computada - Técnica ${ }^{(23)}$ :}

Paciente en decúbito supino con rotación externa de $15^{\circ}$ de las extremidades inferiores ${ }^{(6)}$. Con rodillas en extensión, se realiza un barrido a través de las caderas, rodillas y tobillos y otro barrido a través de las rodillas en flexión en $20^{\circ}$. Se utiliza una técnica de $150 \mathrm{Kv}$ y $5 \mathrm{~mA}$. La rotación externa de las extremidades en $15^{\circ}$ se debe a que se ha descrito que con esta angulación se acentúan las posibles anormalidades de alineamiento y la flexión en $20^{\circ}$ a que la mayor parte de las alteraciones de posición y mala trayectoria se produce en el rango entre $0 \mathrm{y}$ $30^{\circ}$ de flexión (Figura 16).

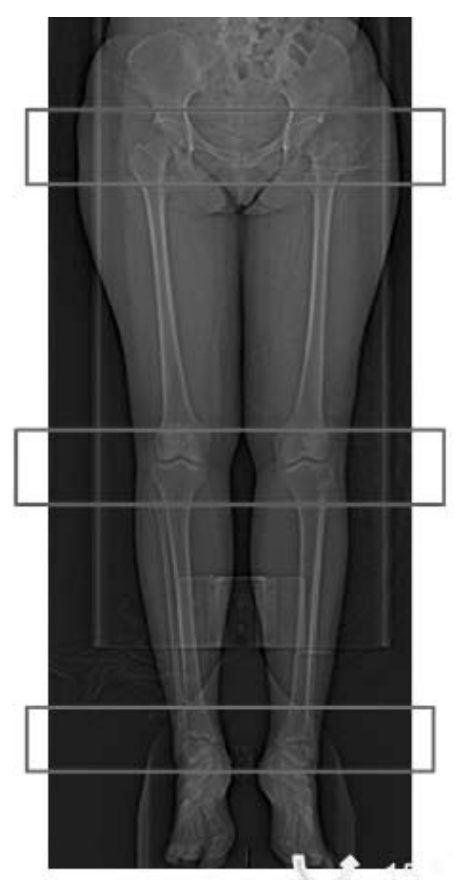

Figura 16. Scout view de estudio de articulación patelofemoral-estudio rotacional de EEII, con campos de visión en caderas, rodillas y tobillos, con extremidades en rotación externa de $15^{\circ}$.

\section{- Evaluación del estudio:}

Se determinan los hallazgos morfológicos más relevantes:

- Lesiones óseas (Figura 17)

- Espacio articular (Figura 18)

- Presencia de derrame articular (Figura 19)

- Alteraciones del retináculo (Figura 20)
- Presencia de osteofitos por tracción (Figura 21).

- Evidencias de cuerpos intraarticulares, masa poplítea o deformación postraumática o postquirúrgica (Figuras 22-24).
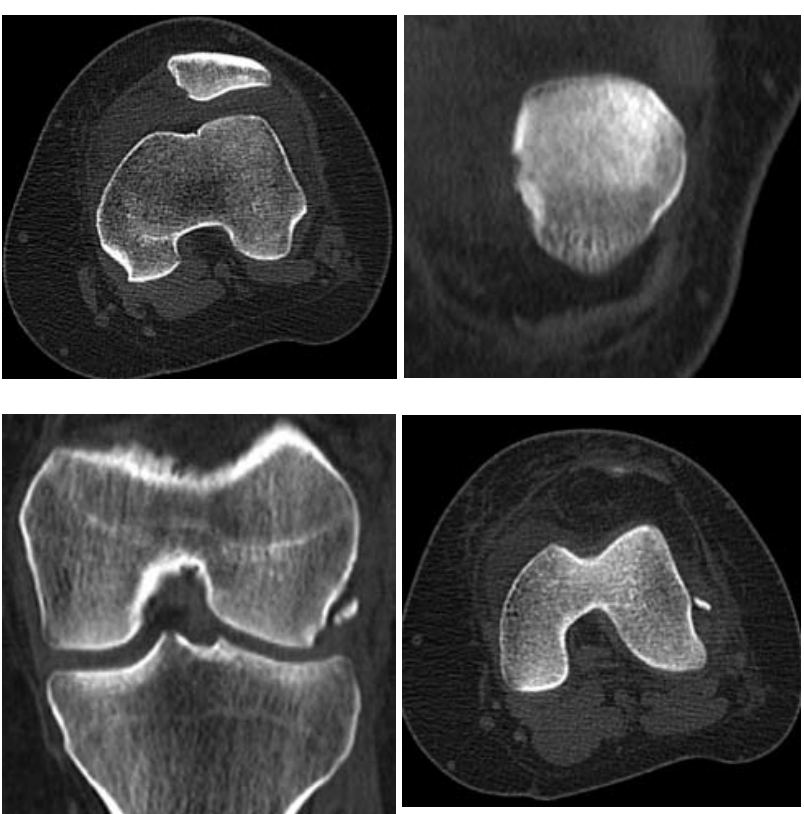

Figura 17. Reconstrucción axial de TC: luxación patelar con fractura osteocondral de la faceta medial y cuerpo libre intraarticular.

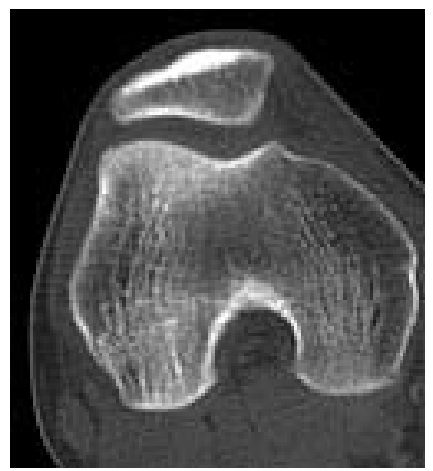

Figura 18. Reconstrucción axial de TC: espacio articular patelofemoral normal.
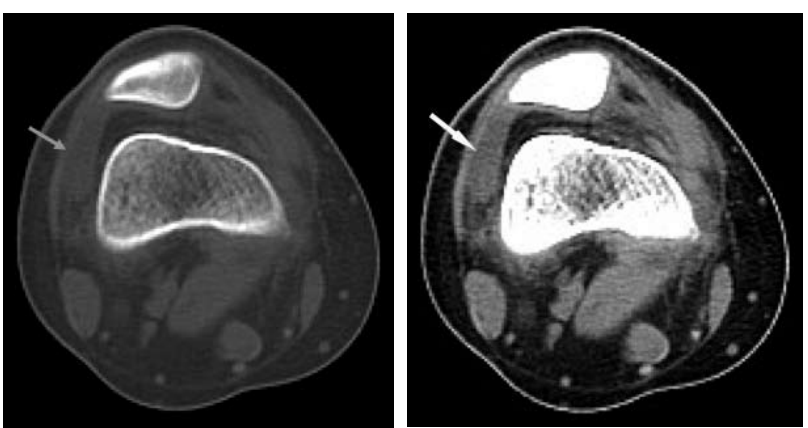

Figura 19. Derrame articular en TC, reconstrucción axial con ventana ósea y de partes blandas. 

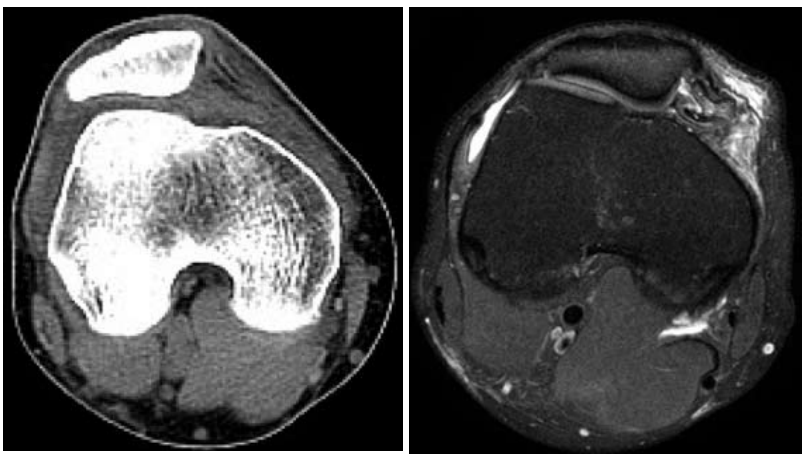

Figura 20. Luxación traumática patelar reducida; se observa rotura del retináculo medial en reconstrucción axial de TC y en RM, DP FS axial.

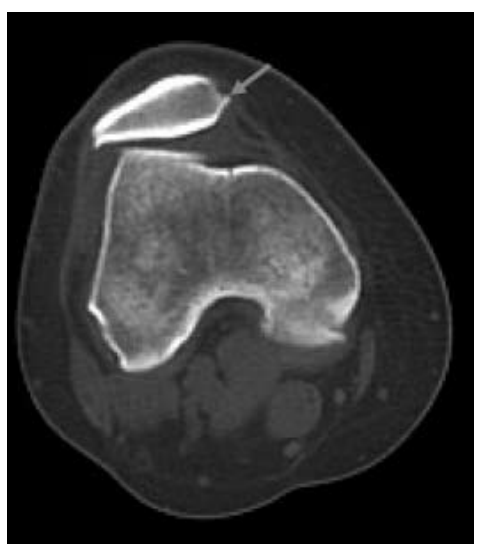

Figura 21. Osteofitos por tracción en faceta patelar lateral y medial, TC reconstrucción axial.
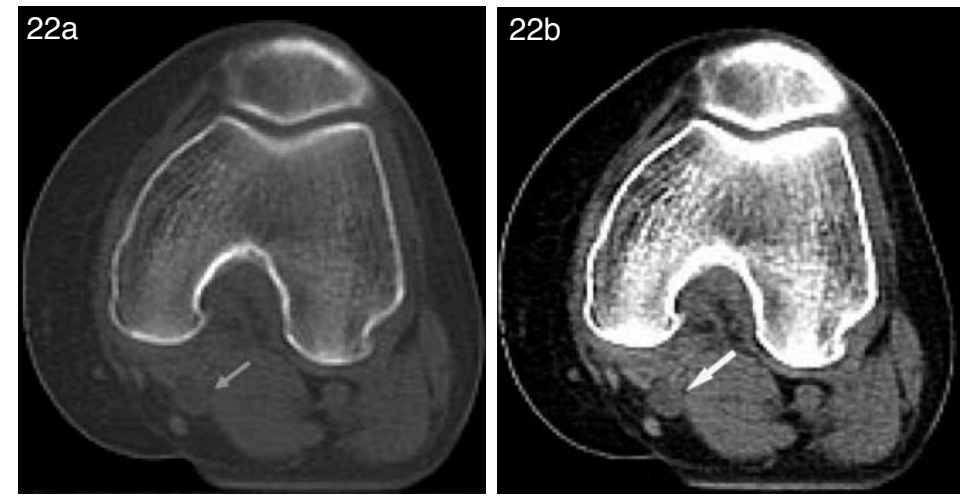
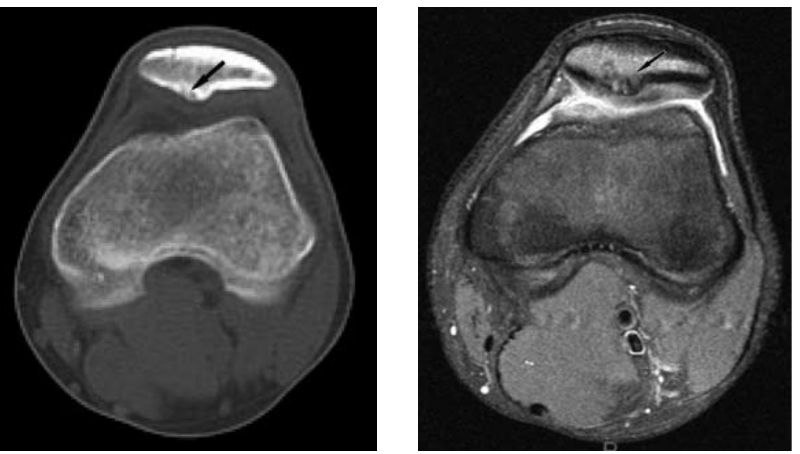

Figura 24. Lesión osteocondral en vértice patelar (fleches), con algunas pequeñas imágenes cistoídeas en TC reconstrucción axial (a) y RM, secuencia DP FS axial (b).

Además se proponen un conjunto de mediciones y clasificaciones, descritas en la literatura, de relevancia clínica para el estudio de DPF:

- Tipo de patela según la clasificación de Wiberg: con las rodillas en extensión (igual a lo descrito en radiología simple).

- Ángulo troclear con rodillas en extensión: Se determina existencia de displasia troclear si el ángulo es mayor a $140^{\circ}$ (igual a lo descrito en Rx simple).

- Displasia troclear con rodillas en extensión: Se clasifica el grado de displasia según la clasificación de Dejour para TC ${ }^{(12)}$ (Figura 25).

Figura 22. Distensión de bursa gastrocnemio semimembranosa con formación de un quiste poplíteo (flecha), TC reconstrucción axial en ventana ósea (a) y de partes blandas (b).

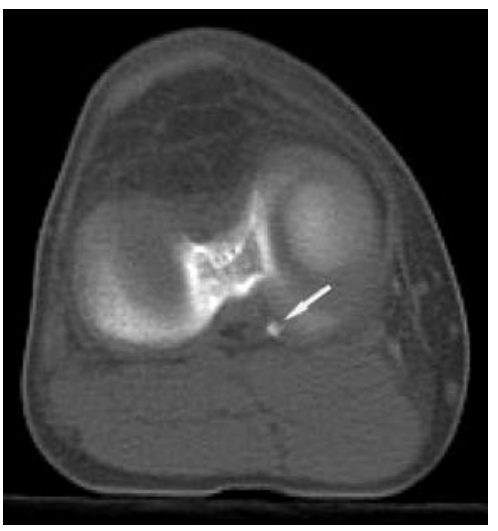

Figura 23. Presencia de cuerpo óseo intraarticular (flecha) en espacio femorotibial posterior, TC reconstrucción axial.

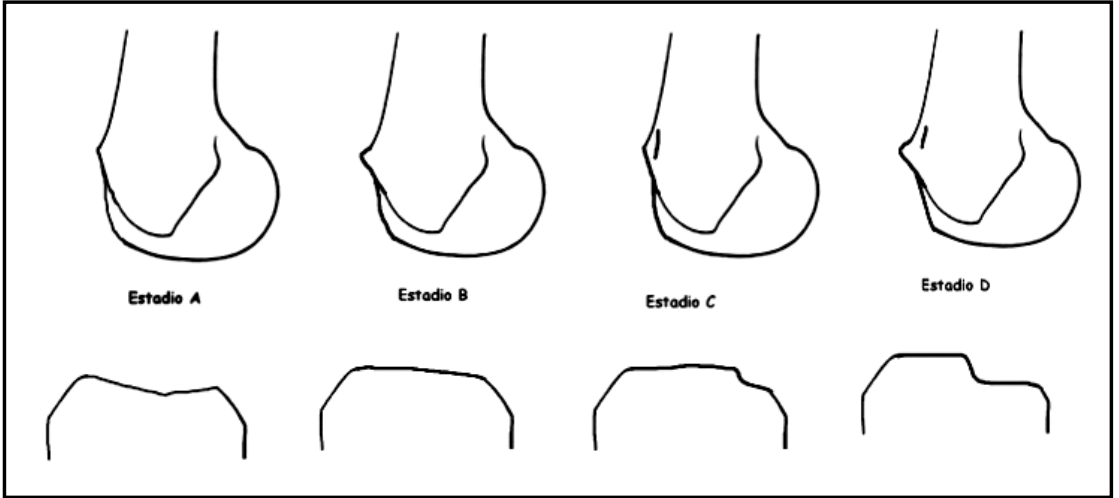

Figura 25. Displasia troclear con rodillas en extension, clasificación de Dejour para TC: tipo A: tróclea aplanada con un ángulo mayor a $140^{\circ}$, tipo B: tróclea plana o convexa, tipo C: hipoplasia del cóndilo femoral medial, tipo D: hipoplasia del cóndilo femoral medial, con unión ósea vertical entre ambas facetas patelares. 
- Altura patelar con rodillas en flexión en 20: Se determina patela en posición normal, baja o alta (igual a lo descrito en Rx simple) ${ }^{(11,24)}$ (Figuras 26, 27). Es importante señalar que estas mediciones descritas para $\mathrm{Rx}$ simple pueden ser homologadas para TC, gracias a que esta última permite realizar reconstrucciones en los 3 planos y en este caso las mediciones de altura patelar son realizadas en una reconstrucción sagital.

- Espolón supratroclear en flexión de $20^{\circ}$, según Dejour ${ }^{(6)}$. Se determina presencia o ausencia de una prominencia supratroclear en la reconstrucción sagital (igual a lo descrito en Rx simple).

- Congruencia rotuliana en flexión de $20^{\circ}$, según Merchant ${ }^{(25)}$. Se realiza la medición al igual a lo anteriormente señalado en Rx simple y se determina existencia de subluxación lateral o medial patelar (Figura 28).

- Ángulo patelofemoral en flexión de $20^{\circ}$, según Laurin ${ }^{(17)}$. Se traza una línea horizontal que pasa por el aspecto más anterior de ambos cóndilos femorales y otra horizontal que pasa por el aspecto posterior de la faceta lateral y se determina si estas líneas se abren hacia lateral, como sucede en articulaciones normales o hacia medial o son paralelas, de forma patológica (Figura 29).

- Distancia SIT - TAT en extensión, según Dejo$u^{(6)}$.

- Tilt patelar externo en extensión, según Dejour ${ }^{(6)}$ (Figura 30).

Figura 28. Ángulo de congruencia según Merchant, con rodillas en flexión en $20^{\circ}$.
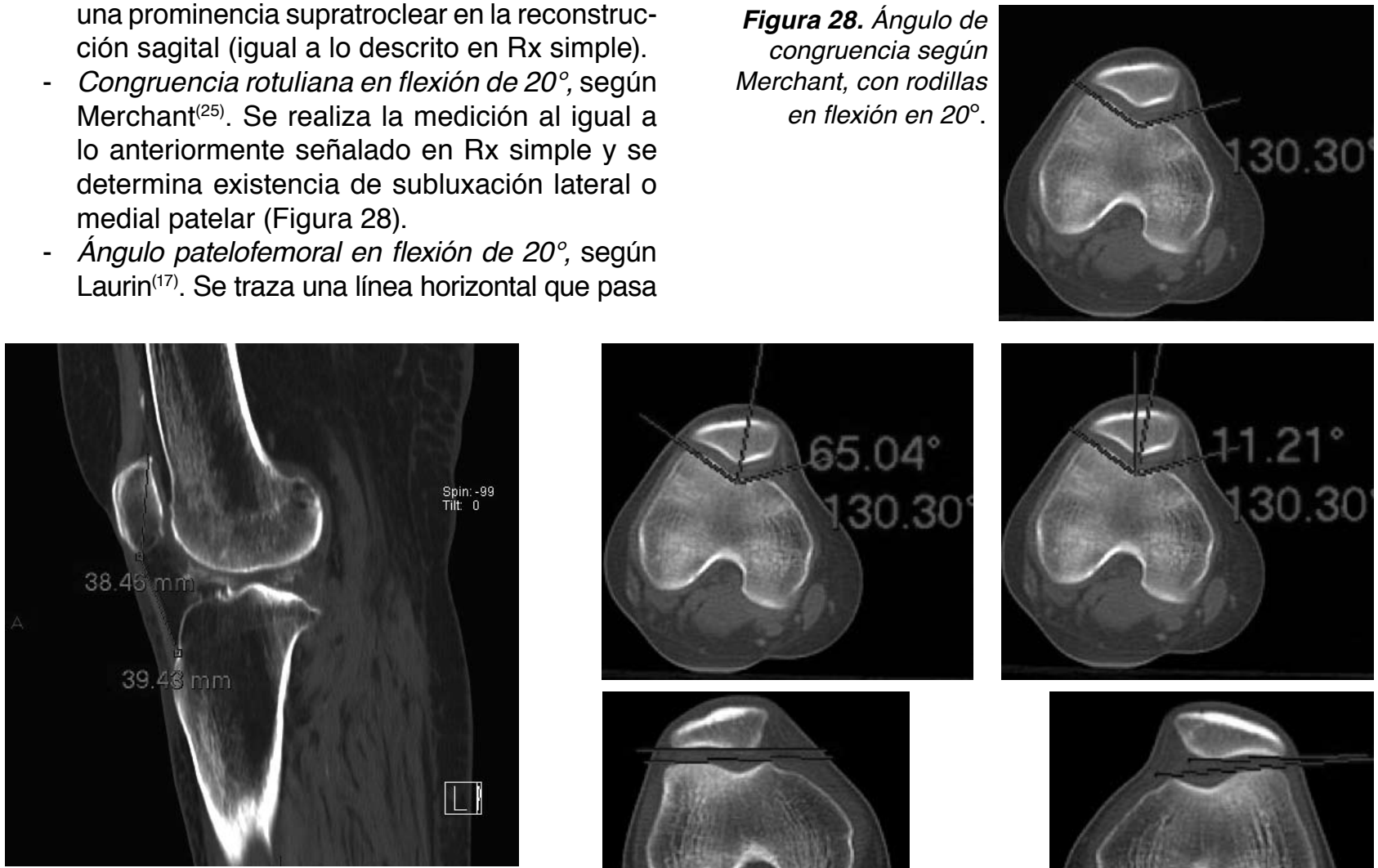

Figura 26. Insall Salvatti en reconstrucción sagital de TC; paciente con cambios de aspecto degenerativo y condrocalcinosis.

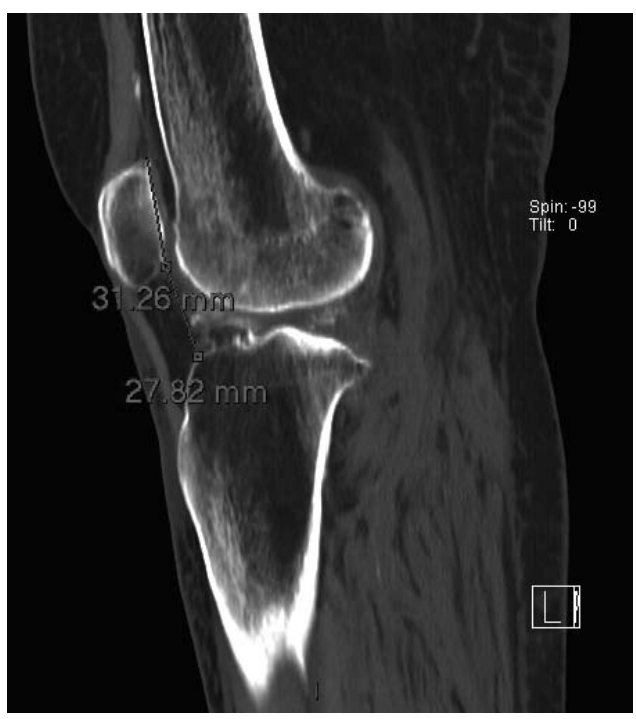

Figura 27. Catonen TC reconstrucción sagital, mismo paciente de Figura 26.
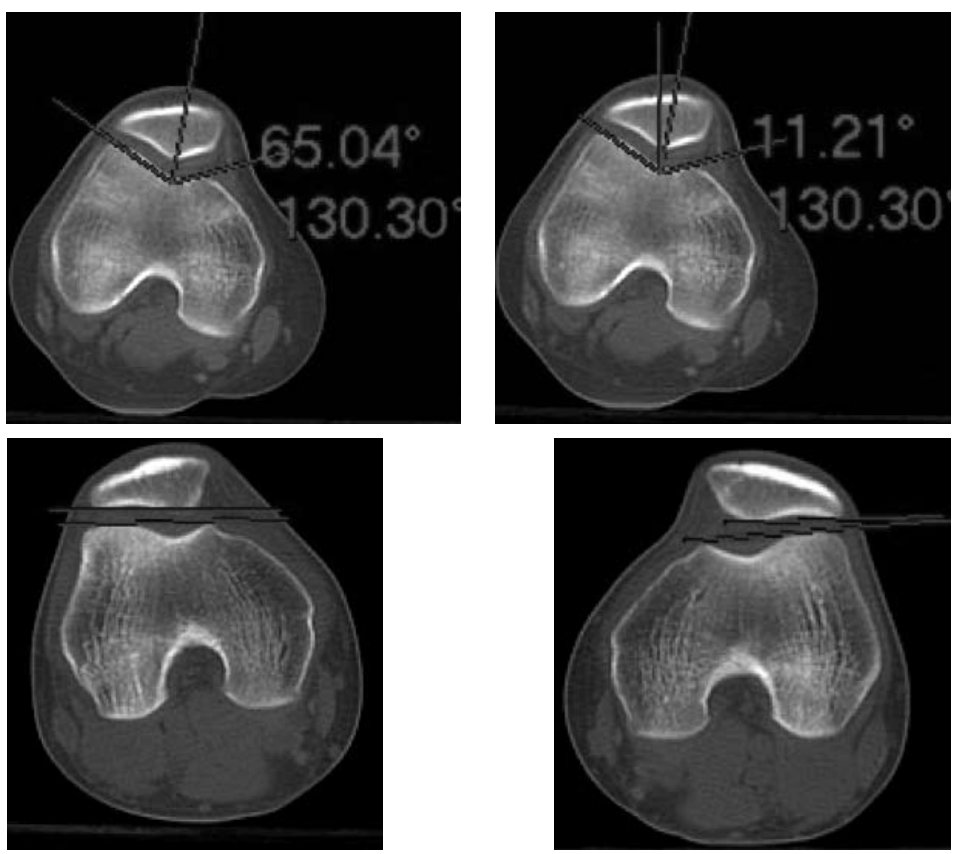

Figura 29. Ángulo patelofemoral de Laurin en flexión en $20^{\circ}$, patológico: paralelo y abierto lateral.

Figura 30. Tilt patelar externo patológico según Laurin (mayor a 20\%); medición efectuada con

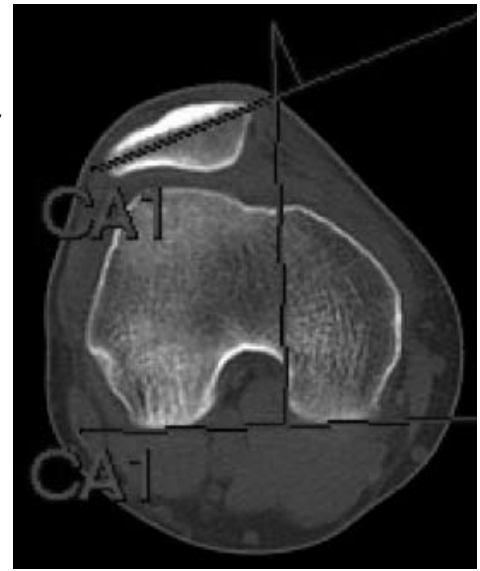
rodilla en flexión en $20^{\circ}$. 
Se incluye la clasificación de Iwano para la presencia de artrosis patelofemoral, ya que las anomalías de alineamiento de la extremidad inferior y otros factores como la displasia troclear, malrotación tibial, dirección/ magnitud de la carga del cuádriceps, etc., pueden jugar un rol en el desarrollo de la alteración, desde condromalasia hasta artrosis en etapas avanzadas $^{(26)}$.

Artrosis en extensión, según Iwano(27). Se determina si existen evidencias de enfermedad degenerativa articular, clasificando en:

Grado I: Fenómenos de remodelación.

Grado II: Disminución de amplitud del espacio articular, con espacio mayor de $3 \mathrm{~mm}$.

Grado III: Disminución de amplitud del espacio articular, con espacio menor de $3 \mathrm{~mm}$.

Grado IV: Contacto hueso-hueso.

A continuación se realiza el estudio rotacional de extremidades inferiores, en extensión, según Ballester y se determina:

- Anteversión acetabular: Se elige el corte a nivel de las cabezas femorales para trazar una línea horizontal que conecte el centro de las cabezas femorales, luego una línea perpendicular a ésta, pasando por el margen lateral de la pared acetabular posterior y una ultima línea que une los márgenes laterales de las paredes acetabulares anterior y posterior. El ángulo entre la línea perpendicular y la que une las paredes acetabulares corresponde al ángulo de anteversión femoral(28). El valor normal es de $15 \pm 5^{\circ(11)}$ (Figura 31) Esta medición no es actualmente incluida en nuestro protocolo ya que los estudios a la fecha sugieren que la versión acetabular no es un factor común en los problemas rotacionales.

- Anteversión femoral: La AVF es el ángulo formado por el eje del cuello femoral-centro de cabeza y la línea bicondílea posterior. En ocasiones puede resultar imposible trazar una línea por el eje del cuello

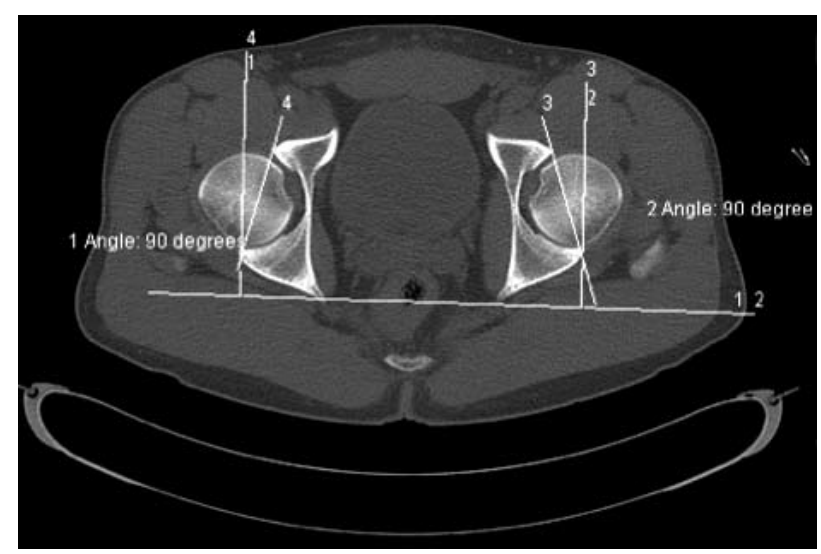

Figura 31. Medición de AVA, en TC. femoral que a la vez pase por el centro de la cabeza femoral, por lo que se deben realizar dos cortes, uno que muestre la cabeza y otro el cuello, que se superponen para trazar el eje del cuello. El eje bicondíleo posterior se obtiene trazando una tangente en el borde posterior de ambos cóndilos femorales. Es importante que en este corte la escotadura intercondílea no represente más de un tercio de la altura del macizo condíleo en sentido anteroposterior. El valor normal está definido en $14 \pm 7^{\text {(23) }}$ (Figura 32).

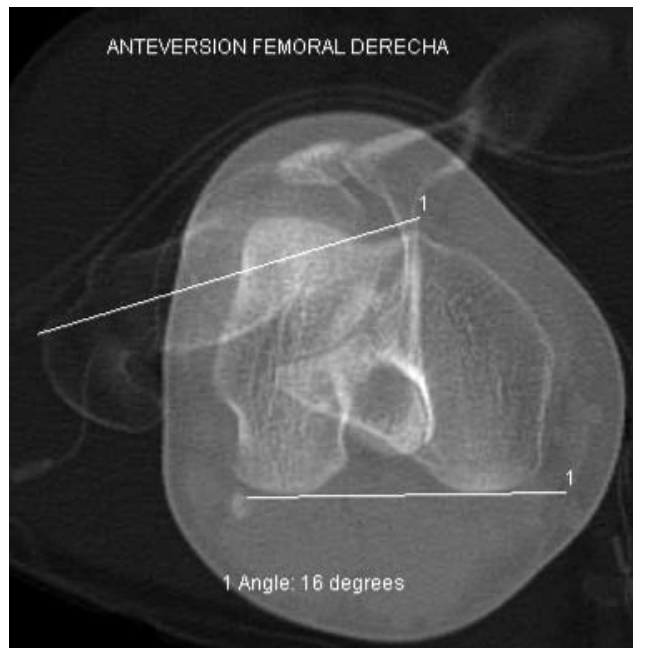

Figura 32. Medición de AVF, en TC.

- Torsión tibial externa: Se mide entre el eje tibial posterior y el eje bimaleolar. El eje tibial posterior se traza como una línea paralela al margen posterior de la tibia proximal. Este corte debe ser lo más cercano posible a la superficie articular, ya que la torsión tibial se produce proximal a la TAT; el eje bimaleolar se traza entre los maléolos tibial y peroneo. El valor normal está definido en $25 \pm 7^{\circ(23)}$. Cabe destacar que, independiente de los valores medidos, toda diferencia entre ambas extremidades inferiores superior a $8^{\circ}$ debe considerarse patológica ${ }^{(23)}$ (Figura 33).

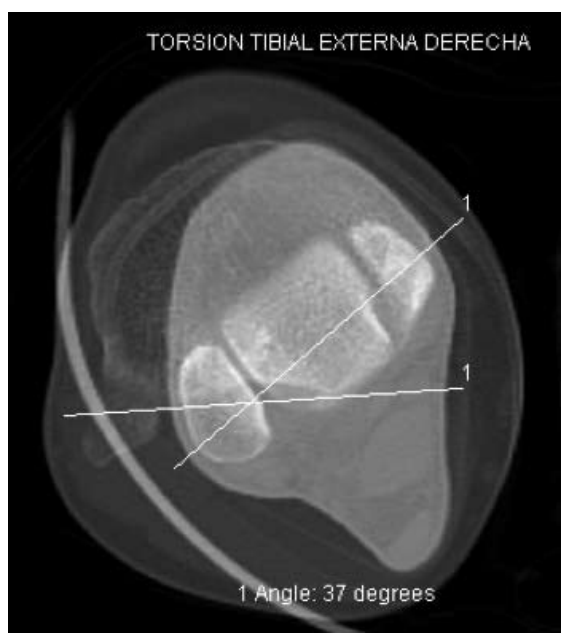

Figura 33. Medición de TTE, en TC. 
Se sistematiza esta información en dos tablas, que dividen la información en alteraciones locales de la APF y alteraciones rotacionales de las extremidades inferiores (Tabla II).
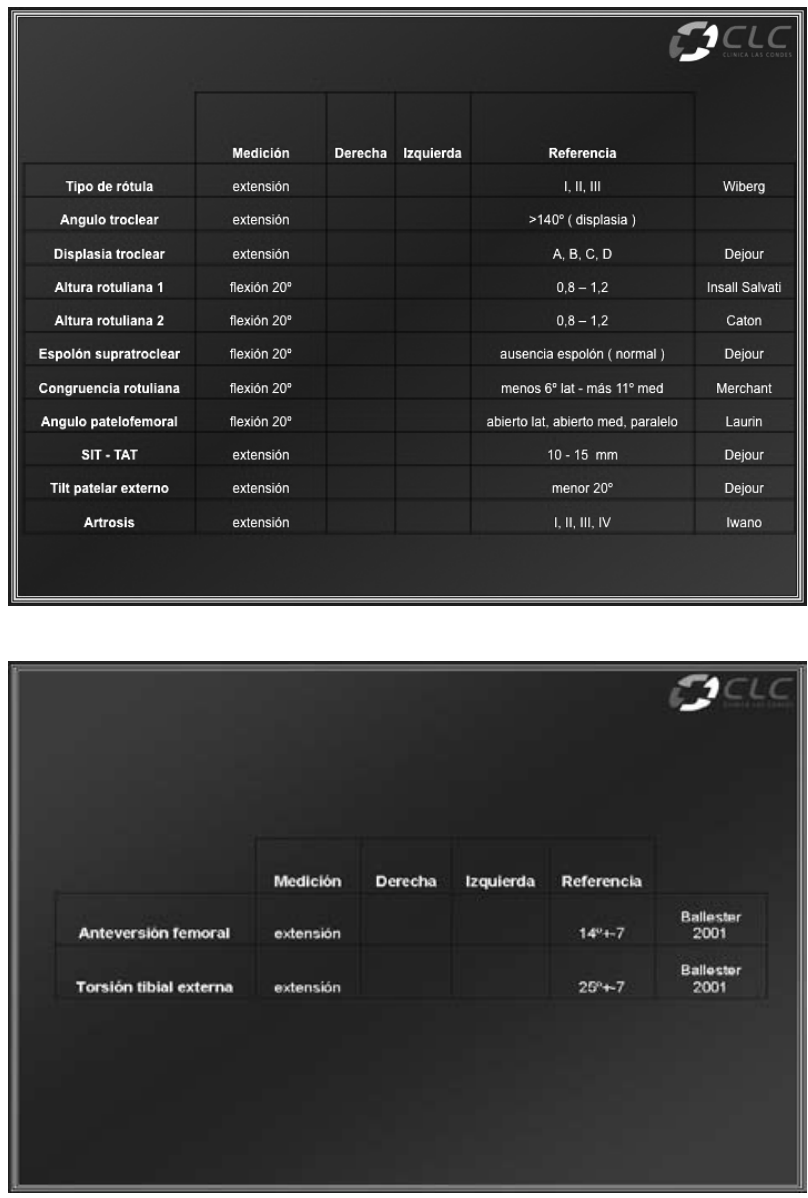

Tabla II. Esquema de sistematización de medidas en el informe del estudio por imágenes de pacientes con DPF.

Finalmente, se intenta llegar a una impresión diagnóstica que concluya los puntos determinantes en la DPF, principalmente la presencia o ausencia de displasia troclear y posición de patela: subluxación, subluxación más tilt o sólo tilt patelar. Estos puntos son determinantes, ya que estos grupos de pacientes tienen sintomatologías y conductas terapéuticas distintas $^{(2)}$.

En el informe se agrega además, si es que existen, los hallazgos morfológicos relevantes asociados y las alteraciones puntuales de las mediciones realizadas antes señaladas. Es importante destacar que mediciones alteradas aisladas no constituyen un diagnóstico; se han descrito pacientes asintomáticos con mediciones alteradas y viceversa, por lo que estas mediciones deben ser evaluadas en el contexto clínico de cada paciente, lo cual se deja explícito en cada informe radiológico.

\section{Conclusiones}

La patología de la APF es un tema aún no esclarecido desde el punto de vista clínico ni radiológico, existiendo múltiples factores involucrados descritos, tanto anatómicos como dinámicos.

La radiología aporta principalmente el análisis de factores anatómicos estáticos, tanto locales como rotacionales, si bien estos últimos aún no han sido comprendidos a cabalidad.

En esta revisión se intenta proponer el estudio radiológico a realizar en pacientes con DPF, determinando los puntos relevantes a señalar con las distintas técnicas de estudio.

Se realiza además una propuesta de estudio tomográfico de la APF, de segunda línea, que incluye además un estudio rotacional de extremidades inferiores, proponiendo los puntos a considerar y las mediciones más relevantes desde el punto de vista radiológico-clínico con la información disponible a la fecha, sistematizados en una plantilla de informe.

Debemos recordar siempre que la valoración del estudio imaginológico debe realizarse en el contexto clínico de cada paciente.

\section{Bibliografía}

1. Fulkerson J, Shea K. Disorders of patellofemoral alignment. J Bone Joint Surg Am 1990; 72: 1424-1429.

2. Dejour $H$, Neyret $P$, Walch $G$. Factors in patellar instability. Knee surgery current practice. Martin Dunitz Itd 1992: 403-412.

3. Hinarejos Gómez P. Desarrollo evolutivo torsional de las extremidades inferiores. J. Ballester. Monografías SECOT 2. Desalineaciones torsionales de las extremidades inferiores. Implicaciones clínicopatológicas. Primera edición. Barcelona: Masson 2000; 3-9.

4. DiGiulio M, Donaldson W. Complications of patello femoral joint surgery. Sports Med Arthrosc Rev 2004; 12: $172-184$

5. Grelsamer R. Patellar malalignment. J Bone Joint Surg Am 2000; 82: 1639-2000.

6. Dejour H, Walch G, Nove-Josserend L, Guier Ch. Factors of patellar instability: an anatomic radiographic study. Knee Surg. Sports Traumatol, Arthroscopy 1994; 2: 79-26.

7. Grelsamer R, Stein DA. Patellofemoral arthritis. J Bone Joint Surg Am 2006; 88: 1849-1860.

8. Grelsamer R. Patellar Nomenclature. Clinical Orthopaedics and Related Research 2005; 436: 60-65.

9. Shellock F, Powers C. Kinematic MRI of the joints: functional anatomy, kinesiology, and clinical applications. United States of America 2001; part IV: 149-170.

10. Amis A. Current concepts on anatomy and biomechanics of patellar stability. Sports Med Arthrosc Rev 2007; 15: 48-56.

11. Biedert R. Patellofemoral Disorders: Diagnosis and treatment. Primera edición. Swizerland. Wiley 2004; 87-131.

12. Chiang A, West R. Current concepts review: patellar instability. J Bone Joint Surg Am 2008; 90: 27512762.

13. Lancourt JE, Cristini JA. Patella alta and patella infera. 
Their etiological role in patellar dislocation, chondromalacia and apophysitis in tibial tubercle. J bone joint Surg Am. 1975; 57: 1112-1115.

14. Shabshin N, Scweitzer M, Morrison W, Parker L. MRI criteria for patella alta and baja. Skeletal Radiol 2004; 33: 445-460.

15. Wiberg G. Roentgenographic and anatomic studies on the femoropatellar joint. Acta Orthop Scand 1941; 12: 319-410.

16. Ashley J, Amis A, Andrish J, Arendt E, Erasmus P, Powers C. Surgical biomechanics of the patellofemoral joint. Arthroscopy: The Journal of arthroscopic and related surgery 2007; 23: 542-553.

17. Laurin CA, Lavesque HP, Dussault R, Labelle H, Peides JP. The abnormal lateral patellofemoral angle: $A$ diagnostic reontgenographic sign of recurrent patellar subluxation. J Bone Joint Surg Am 1978; 60: 55-60.

18. Grelsamer R, Weinstein C, Gould J, Dubey A. Patellar tilt: The physical examination correlates with MR imaging. The Knee Journal 2008; 15: 3-8.

19. Losada Bardeci P. Alteraciones de los miembros inferiores: Deformidades angulares, torsionales, alteraciones de la marcha y dismetrías. Pediatr Integral 2002; 6(5): 397-412.

20. Lynn Staheli T. Rotational problems in children. J Bone Joint Surg Am 1993; 75: 934-949.

21. Lee J, Jarvis J, Uhthoff H, Avruch L. The fetal ace- tabulum. A histomorphometric study of acetabular anteversion and femoral head coverage. Clin Orthop 1992; 281: 48-55.

22. Jacquemier M, Jouve JL, Bollini G, Panuel M, Migliani R. Acetabular anteversion in children. J Pediat Orthop 1992; 12: 373-37.

23. Solano A, Brill Kremer W, Tey Pons M, Espiga Tugas $X$. Normoalineación de las extremidades inferiores en el adulto. J Ballester Monografías SECOT 2. Desalineaciones torsionales de las extremidades inferiores. Implicaciones clinicopatológicas. Primera edición. Barcelona: Masson 2000; pp11-16.

24. Donell S. Patellofemoral dysfunction-extensor mechanism malalignment. Current Orthopaedics 2006: 20; 103-111.

25. Merchant A, Mercer R, Jacobsen R, Cool C. J Bone Joint Surg Am 1974; 56: 1391-1396.

26. Becker R, Röpke M, Krull A, Musahl V, Nebelung W. Surgical treatment of isolated patellofemoral osteoarthritis. Clin Orthop Relat Res 2008; 466(2): 443-449.

27. Dejour D. Protheses du genou et systeme extensour. 12eme journees lyonnaises de chirurgie du genou. Maitrise orthopedic. Le journal orthopedic sur la web 2007; 163.

28. Keats T, Sistrom C. Atlas de Medidas Radiológicas. Séptima edición. España. Elsevier 2002; pp.233234. 